\title{
An unanticipated case of heterotopic pregnancy
}

\author{
Shalini Chawla*, Nashwa Abulhassan
}

Department of Obstetrics \& Gynaecology, St. Helier Hospital, Carshalton, Surrey, UK

Received: 24 January 2016

Accepted: 01 March 2016

\section{*Correspondence:}

Dr. Shalini Chawla,

E-mail: shalinichawla72@yahoo.co.uk

Copyright: $\odot$ the author(s), publisher and licensee Medip Academy. This is an open-access article distributed under the terms of the Creative Commons Attribution Non-Commercial License, which permits unrestricted non-commercial use, distribution, and reproduction in any medium, provided the original work is properly cited.

\section{ABSTRACT}

The objective of this article is to raise awareness of an increase in incidence of spontaneous heterotopic pregnancies which may be secondary to tubal damage caused by underlying pelvic inflammatory disease or may occur without any risk factors. A high index of clinical suspicion coupled with increased diagnostic sonographic accuracy and meticulous follow-up will aid appropriate management of both intra and extra uterine components of a heterotopic gestation. This is a case of unanticipated heterotopic pregnancy that was initially diagnosed as ectopic pregnancy. Intra-uterine pregnancy was subsequently detected post operatively during follow up. Follow-up of all salpingectomies through a urine pregnancy test may aid in picking up cases of heterotopic pregnancy that were missed at initial presentation either clinically or on ultrasound. Increased vigilance will improve the management of a complex condition that poses a diagnostic dilemma.

Keywords: Heterotopic pregnancy, Ectopic pregnancy, Diagnosis, Management

\section{INTRODUCTION}

A heterotopic pregnancy is one where one embryo is implanted in the uterus and the other embryo is implanted elsewhere as an ectopic pregnancy. The word 'heterotopic' arises from the Greek words 'hetero' and 'topos' meaning 'other' and 'place' respectively.

The majority of heterotopic pregnancies reported are a combination of an intrauterine pregnancy with another pregnancy in the ampullary portion of the fallopian tube. ${ }^{1,2}$ Other types of heterotopic pregnancies include intrauterine pregnancy in addition to location of a pregnancy in unusual sites such as interstitial portion of the fallopian tube, rudimentary horn associated with a unicornuate uterus, ovary, cervix, pregnancy at the site of a previous caesarean section scar or intra-abdominal. ${ }^{3-7}$

Traditionally the incidence of spontaneous heterotopic pregnancy has been quoted as 1 in 30,000 but more recent literature estimates this to be of the order of 2.5/10,000 pregnancies and it can be as high as 1 in 100 with assisted reproduction treatments. ${ }^{2,8-11}$ The incidence of heterotopic pregnancy is rising and that can be attributed to a rise in its risk factors namely pelvic inflammatory disease, ovulation induction treatments and assisted reproduction treatment. ${ }^{11-13}$

We report a case of a heterotopic pregnancy where the initial presentation was that of an acute abdomen due to haemoeritoneum caused by leakage from a tubal ectopic pregnancy. A co-existent intrauterine pregnancy was only identified on post salpingectomy follow up through a persistently positive urine pregnancy test.

\section{CASE REPORT}

A 32 year old lady presented to Accident and Emergency Department at 3 am with a two day history of worsening abdominal pain, particularly in right iliac fossa associated with diarrhoea and one episode of vomiting. She reported loss of appetite and feeling faint whilst at work. The last menstrual period was 26 days ago and there was no history of vaginal bleeding. She had no previous pregnancies and was in a stable relationship. She had just discontinued contraception and the couple were planning to start a family. She had no risk factors for pelvic 
inflammatory disease (PID) and maintained a high level of personal fitness.

On arrival, she was found to be normotensive (BP 107/72) and had borderline tachycardia of 99/min. Following four hours of waiting in the Department, she reported worsening of symptoms and a repeat assessment showed that she was hypotensive at $83 / 52 \mathrm{mmHg}$ with pulse rate of $85 / \mathrm{min}$. She was transferred to A/E Resus and was given fluid resuscitation by emergency department that promptly restored her BP to $110 / 60$ $\mathrm{mmHg}$. She subsequently maintained her pulse rate at approximately 80 beats/ min and BP between $110-120$ / 60-70 $\mathrm{mmHg}$ over the next few hours. She was apyrexial (temp $36.0 \mathrm{C}$ ) and had normal respiratory rate and oxygen saturation. On abdominal examination, there was diffuse tenderness in the lower abdomen and rebound symptoms in right iliac fossa predominantly at $\mathrm{Mc}$ Burney's point. A urinary catheter was passed and she was found to be pregnant on a urine pregnancy test. A referral was made to Gynaecology team for urgent review.

She was reviewed immediately by the gynaecology team who agreed with the above examination findings of rebound tenderness in the lower abdomen. The differential diagnoses at this stage were ectopic pregnancy or sepsis due to acute appendicitis. Initial blood results showed haemoglobin of $124 \mathrm{~g} \%$ with a raised white blood cell count (WCC) of 21.5 and urea of 7.5. A venous blood gas showed base excess of -8.9 and lactate of 7.4. A repeat arterial blood gas confirmed metabolic acidosis with $\mathrm{pH}$ of 7.23 and lactate of 5.7. As she was hemodynamically stable, plan was made to give fluid resuscitation, broad spectrum intravenous antibiotics, perform a transvaginal scan and seek surgical opinion.

Transvaginal scan performed soon after by a consultant gynaecologist showed an intrauterine sac with mean sac diameter measuring $2.9 \mathrm{~mm}$. The sac did not demonstrate a trophoblastic ring around it and was thought to be a pseudosac (Figure 1). Scanning the adnexae revealed a 30x30 mm left adnexal mass with evidence of gestation sac, yolk sac and a fetal pole measuring $4.9 \mathrm{~mm}$ (Figure 2 ). There was no demonstrable fetal heart activity. There were significant mixed heterogenic areas in pouch of Douglas suggestive of a large hemo-peritoneum.

She underwent emergency laparoscopic surgery. A distended, bluish left tubal ectopic pregnancy with 4 litres of blood was seen in the peritoneal cavity (Figure 3). Left salpingectomy was performed with peritoneal washout. 3 units of blood transfusion were given intraoperatively as she had dropped her haemoglobin from 124 to $60 \mathrm{~g} \%$. Postoperatively she made a good recovery and was discharged home on the next day. She was advised to repeat the urine pregnancy test at home in 3 weeks and call Early Pregnancy Unit if still positive.

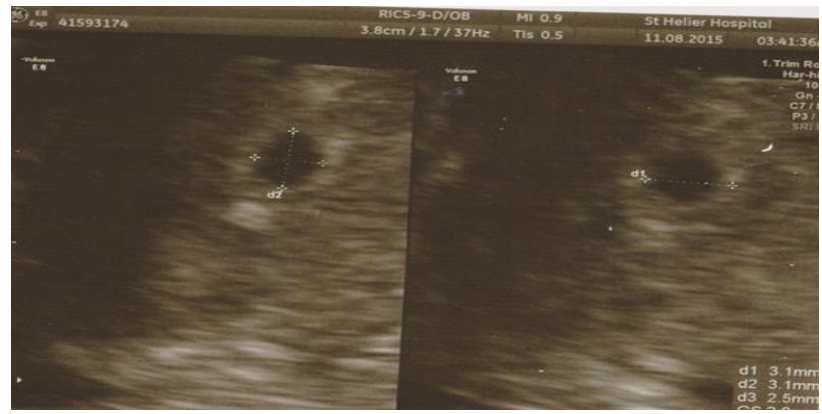

Figure 1: Initial scan showing intrauterine sac thought to be a pseudosacmeasuring 3.1x $3.1 \times 2.5 \mathrm{~mm}$.

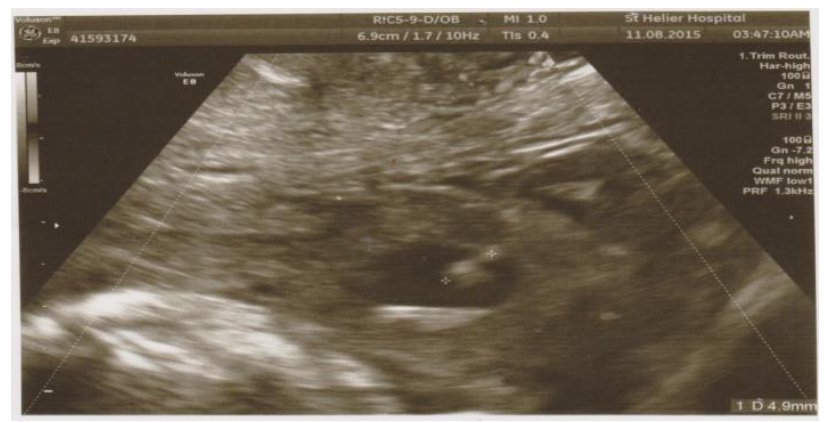

Figure 2: Scan showing adnexal mass with presence of fetus with CRL $4.9 \mathrm{~mm}$.

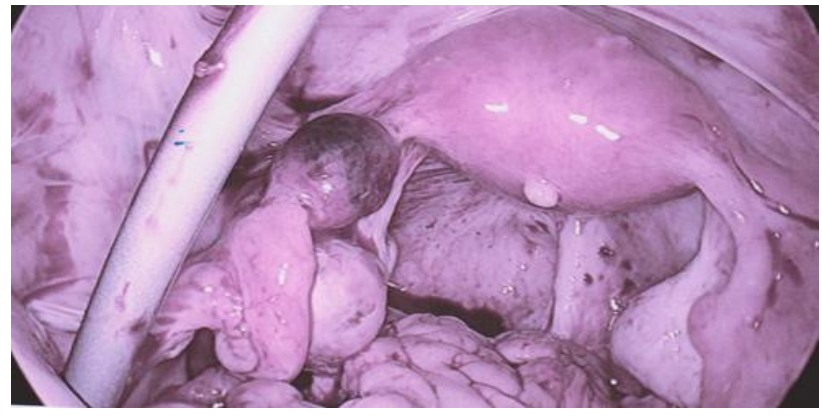

Figure 3: Left tubal pregnancy with hemoperitoneum seen at laparoscopy.

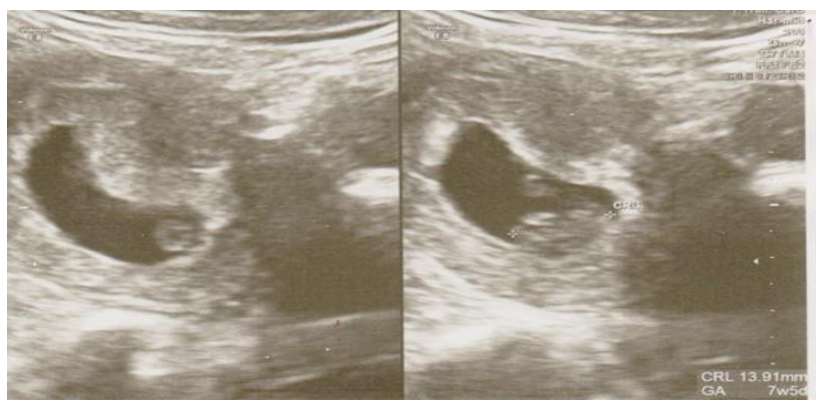

Figure 4: Follow up scan showing intrauterine pregnancy.

Three weeks later, as the home pregnancy test was still positive, she was invited to come to Early Pregnancy Unit where she had serum estimation of human chorionic gonadotrophin $(\mathrm{HCg})$ hormone levels and a transvaginal 
scan. HCg showed doubling from 36 to 64, 000 over 48 hours and scan revealed an ongoing intrauterine pregnancy corresponding to $7+5$ gestation with crownrump length (CRL) of $13.9 \mathrm{~mm}$ and demonstrable fetal heart activity (figure 4). Histology of resected tube confirmed presence of chorionic villi consistent with tubal gestation.

She was pleasantly surprised after the initial shock wore off and we made arrangements for her antenatal care. To date, the pregnancy is progressing well and she has had a normal 20 week anomaly scan.

\section{DISCUSSION}

Heterotopic pregnancy was first described by Duverny in 1708. ${ }^{14}$ Traditionally, incidence of spontaneous heterotopic pregnancy has been quoted as 1 in $30,000 .{ }^{8}$ However, its incidence is rising and that can be attributed to a rise in its risk factors namely PID and tubal damage, ovulation induction treatments and assisted reproduction treatments. ${ }^{10}$ Though there is a high index of suspicion in women undergoing fertility treatments, it is often not considered for spontaneous conceptions. ${ }^{2,9}$

In a recent systematic review it was noted that nearly a third of their cases were diagnosed after a spontaneous conception. $^{2}$ A major factor implicated in causation of ectopic and heterotopic pregnancy is tubal damage that may be unrecognised from PID in early reproductive life. Sexual behaviour in the community has seen a significant change in the last few decades leading to an increased incidence of PID which may or may not be previously known. PID is a recognised risk factor and there is evidence that its incidence in the last two decades has risen; it is therefore not surprising that the incidence of ectopic and spontaneous heterotopic pregnancies is higher than was previously thought. ${ }^{1,2,10}$ Indeed, a previous ectopic pregnancy and history of pelvic surgery are considered as independent risk factors for a heterotopic pregnancy. Sometimes presence of risk factors can be a clue to the diagnosis as women with assisted conception or tubal damage are known to be at higher risk thereby increasing our index of clinical suspicion. However, there may not be any risk factors at all as was the case in our report making the diagnosis very difficult. ${ }^{2}$

The usual clinical presentation of heterotopic pregnancies is fairly typical of any early pregnancy complication such as abdominal pain, bleeding, hemodynamic instability or as an incidental finding on a routine scan. Theoretically, an ultrasound would be conclusive but anecdotally, the diagnosis was missed in $75 \%$ of the cases reported by Barrenetxea et al and $33 \%$ of the cases in more recent literature. $^{2,15}$ High resolution ultrasound machines, better training, more awareness have increased the diagnostic ability but sonographic diagnosis of heterotopic pregnancy in current literature still stands at $66 \%$ with $29 \%$ being diagnosed during surgery. ${ }^{2,16}$ Diagnostic dilemma arises during scanning when identification of an intra-uterine pregnancy can distract the sonographer and the clinician to the possibility of a co-existent ectopic pregnancy. At the time of the initial scan, either an ectopic pregnancy can be completely missed or reported as an adnexal mass. Cases have been reported in literature where an erroneous diagnosis of haemorrhagic corpus luteum or ovarian tumour was given to an adnexal mass that was subsequently found to be an ectopic pregnancy. ${ }^{9,17,18}$ Acute presentations with an intrauterine pregnancy have been misconstrued as ovarian cyst accident with the pathology subsequently revealing itself either during surgery or in histology specimens. ${ }^{9,19}$ A relatively fewer number of cases have been reported in literature of the reverse scenario where the initial presentation was due to the ectopic pregnancy and management focussed on initial stabilisation of the patient and treatment of the ectopic pregnancy and the intrauterine component came to light after the acute event. $^{20}$

Heterotopic pregnancy is a dangerous condition as the false reassurance of seeing an intrauterine pregnancy detracts from the serious risks posed by the ectopic. ${ }^{21}$ Any clinical symptoms get attributed to either the normal pregnancy spectrum or a surgical pathology. As stated by Talbot et al, the dictum 'think ectopic' is forgotten in presence of an intra-uterine pregnancy with potential serious consequences. ${ }^{2}$

Likewise, the management of the intrauterine component of the pregnancy (IUP) is crucial. Though there is a slightly higher risk of miscarriage compared to an isolated intra-uterine pregnancy, recent studies have quoted survival in the order of $60-70 \%$. Survival rate was reported as $69 \%$ by Barrenetxea and $66 \%$ by Talbot et al which is a significant improvement from $51 \%$ as reported by Winer in $1957 . .^{2,15,22,23}$ Clayton et al reported that risk of adverse outcomes such as low birth weight and preterm delivery is not significantly different in ongoing intrauterine component of heterotopic pregnancies as compared to isolated IUP. ${ }^{22}$ Though some studies have suggested a guarded prognosis for very early intervention $<6$ weeks or late intervention $>8$ weeks, ${ }^{[24]}$ the overall prognosis for the intrauterine pregnancy is excellent as published in literature. Therefore, care must be taken to optimise outcomes through appropriate detection of a heterotopic pregnancy and subsequent management of both intra- uterine and extra- uterine components.

In our case, the intrauterine pregnancy was detected due to the follow- up arranged post salpingectomy. Though our intention to ask her to do a urine pregnancy test was to exclude persistent trophoblastic disease, an intrauterine pregnancy could have quite clearly been missed with the opportunity for antenatal care lost. Royal College of Obstetrics and Gynaecology (RCOG) guidance does not advocate routine pregnancy testing following salpingectomy but NICE (National Institute of Clinical Excellence) Guidelines do advise urine 
pregnancy testing 3 weeks following salpingectomy for an ectopic pregnancy. ${ }^{25,26}$

In our experience, in most units in the UK, though histology specimens are checked to confirm extra-uterine gestation, no further follow up is arranged following salpingectomy for confirmed ectopic pregnancies. However, serum BhCG is routinely done for follow- up of salpingotomies performed for ectopic pregnancies when contralateral tube is damaged or following methotrexate administration. ${ }^{25}$ A case can be made for follow up of all salpingectomies with home urine pregnancy tests after 3 weeks. It is a cheap and convenient test self -administered by the patient and could help to exclude heterotopic pregnancies and persistent trophoblastic tissue.

As the incidence of spontaneous heterotopic pregnancy is rising and ultrasound still misses a third of these cases, it would be prudent to adopt a high index of clinical and sonographic suspicion and promote simple practices like routine urine testing following salpingectomies so that similar cases don't slip through the net with potential adverse consequences for mother and baby.

Funding: No funding sources Conflict of interest: None declared

Ethical approval: Not required

\section{REFERENCES}

1. Rabbani I, Polson DW. Heterotopic pregnancy is not rare. A case report and literature review. Journal of Obstetrics and Gynaecology. 2005;25:204-5.

2. Talbot K, Simpson R, Price N, Jackson SR. Heterotopic pregnancy. Journal of Obstetrics and Gynaecology. 2011;31(1):7-12.

3. Alnaggar E, Edmonds H. Spontaneously conceived ovarian heterotopic pregnancy: Case report. BJOG: An International Journal of Obstetrics and Gynaecology. 2015;122(17):1470-0328.

4. Lallar M, Nandal R, Sharma D. Unruptured rudimentary horn pregnancy presenting with acute haemoperitoneum with combined intrauterine pregnancy: A case report. Iranian Journal of Reproductive Medicine. 2015;13(1):49-52.

5. Tsakos E, Tsagias N, Dafopoulos K. Suggested method for the management of heterotopic cervical pregnancy leading to term delivery of the intrauterine pregnancy: Case report and literature review. Journal of Minimally Invasive Gynecology. 2015;22(5):896901.

6. Croce P.; Panzeri L.; Perotti D.; Zanchi S.M .Diagnosis and therapy of heterotopic interstitial pregnancy with progression of intrauterine twin. Gazzetta Medica Italiana Archivio per le Scienze Mediche. 2014;173(10):533-7.

7. Uysal F, Uysal A. Spontaneous heterotopic cesarean scar pregnancy: conservative management by transvaginal sonographic guidance and successful pregnancy outcome. Journal of ultrasound in medicine: official journal of the American Institute of Ultrasound in Medicine. 2013;32(3):547-8.

8. DeVoe RW, Pratt JH. Simultaneous intrauterine and extrauterine pregnancy. American Journal of Obstetrics and Gynaecology. 1948;56:1119-26.

9. Khalil A, Momin S, Yaakub HR. Case report: A rare case of ruptured heterotopic pregnancy with intrauterine pregnancy reaching term with good obstetric outcome. BJOG: An International Journal of Obstetrics and Gynaecology. 2015;122(2122):1470-0328.

10. Rizk B. Outcome of assisted reproductive technology. In: Brinsden PR, eds. A textbook of in vitro fertilisation and assisted reproduction. The Bourn Hall guide to clinical and laboratory practice. 2nd ed.: CRC Press; 1999:316-317.

11. Molloy D, Deambrosis W, Keeping D, Hynes J, Harrison K, Hennessey J. Multiple- sited (heterotopic) pregnancy after in vitro fertilization and gamete intrafallopian transfer. Fertility and Sterility. 1990;53:1068-71.

12. Reece EA, Petrie RH, Sirmans MF, Finster M, Todd WD. Combined intrauterine and extrauterine gestations: a review. American Journal of Obstetrics and Gynecology. 1983;46:323-30.

13. Bello GV, Schonholz D, Moshirpur J, Jeng DY, Berkowitz RL. Combined pregnancy: the Mount Sinai experience. Obstetrical and Gynecological Survey. 1986;41:603-13.

14. DuVerney JG. Oeuvres Anatomiques. In: Jombert CA, eds. Oeuvres Anatomiques. Paris: Bailliere; 1899:355.

15. Barrenetxea G, Barinaga-Rementeria L, Lopez de Larruzea A, Agirregoikoa JA, Mandiola M, Carbonero K. Heterotopic pregnancy: two cases and a comparative review. Fertility and Sterility. 2007;87:417e9-e15.

16. Petrides A, Mahboob S, Sayegh S. Heterotopic pregnancy: A not so rare entity. Ultrasound in Medicine and Biology. 2015;41/4 SUPPL.1(S123S124):0301-5629.

17. Jeri AR. Woman with heterotopic pregnancy after natural conception. BJOG: An International Journal of Obstetrics and Gynaecology. 2015;122(33):14700328.

18. Somers MP, Spears M, Maynard AS, Syverud SA. Ruptured heterotopic pregnancy presenting with relative bradycardia in a woman not receiving reproductive assistance. Annals of Emergency Medicine. 2004;43:382-5.

19. Headley AJ, Adum V. Naturally occurring heterotopic pregnancy in a multiparous patient: A case report. Journal of Reproductive Medicine. 2013;58(11-12):541-4.

20. Wang LL, Chen X, Ye DS, Liu YD, He YX, Guo W. Misdiagnosis and delayed diagnosis for ectopic and heterotopic pregnancies after in vitro fertilization and embryo transfer. Journal of Huazhong University of 
Science and Technology Medical Science. 2014;34(1):103-7.

21. Lewis G, ed. 2007. The confidential enquiry into maternal and child health (CEMACH). Saving mothers' lives: reviewing maternal deaths to make motherhood safer 2003-2005. The Seventh Report on Confidential Enquiries into Maternal Deaths in the United Kingdom. London: CEMACH.

22. Clayton HB, Schieve LA, Peterson HB, Jamieson DJ, Reynolds MA, Wright VC. A comparison of heterotopic and intrauterine only pregnancy outcomes after assisted reproductive technologies in the United States from 1999 to 2002. Fertility and Sterility. 2007;87:303-9.

23. Winer AE, Bergman WD, Fields C. Combined intraand extrauterine pregnancy. American Journal of Obstetrics and Gynecology. 1957;74:170-8.
24. Desai A, Ganesh C, Rao K, Rajan RS. Heterotopic pregnancies - spontaneous versus artificial conceptions. BJOG: An International Journal of Obstetrics and Gynaecology. 2015;122(18-19):14700328.

25. Royal College of Obstetricians and Gynaecologists. The Management of Tubal Pregnancy. Green Top Guideline No. 21. Published 2004, Reviewed 2010. Available at http:// www.rcog.org.uk/ guidelines/ the management of tubal pregnancy. Accessed 1 December 2015.

26. National Institute of Clinical Excellence. Ectopic Pregnancy and miscarriage: diagnosis and initial management. Published 2012. Available at http://www.nice.org.uk/ectopic. Accessed 1 December 2015.

Cite this article as: Chawla S, Abulhassan N. An unanticipated case of heterotopic pregnancy'. Int J Reprod Contracept Obstet Gynecol 2016;5:1228-30. 